\section{Perinatal lessons from the past}

Sir,

May I correct one reference in Dr Dunn's excellent reminder that we often rediscover past knowledge because we forget to review the literature of our predecessors? ${ }^{1}$ The biblical text quoted at the beginning of the article is from Ecclesiastes (the book following Proverbs), and the preceding verse (9) ends '. . . what has been done will be done again, and there is nothing new under the sun.' The book called Ecclesiasticus (found in the Apocrypha) forms another part of the ancient 'wisdom literature', and hints that the doctor and academic may have suffered financial restraints and 'university' squeezes in ancient times too. Chapter 38 verse 1 reminds the reader to ... 'Honour the doctor for his services' . . a and verse 24 of the same chapter states: 'A scholar's wisdom comes from ample leisure; if a man is to be wise he must be relieved of other tasks'.

Yes, there is nothing new under the sun!

\section{Reference}

1 Dunn PM. Perinatal lessons from the past. Arch Dis Child 1989;64:493.

P RoBson

Department of Child Health, King's College Hospital, Denmark Hill, London SE5 9RS

\section{Autosomal recessive hypophosphataemia}

Sir,

In 1976 we described for the first time autosomal recessive hypophosphataemia. ${ }^{1}$ Family testimony and obstetric records leave no doubt as to the identity of the (now deceased) mother of the two affected offspring of the first cousin marriage we reported. The evidence for paternity we cited in our paper was, however, based only upon blood group analysis. In order to confirm paternity beyond doubt, we have re-examined the question using HLA and DR typing and genetic fingerprinting.

HLA and DR typing show the putative father to share one haplotype with the two affected offspring, antigens A11, BW50, and DR7 being common to all three individuals. Genetic fingerprinting (Cellmark Diagnostics) shows the father and his affected son to share 24 bands ( 42 bands identified in the father and 38 in the son). The father and affected daughter share 29 bands ( 42 bands identified in each). Calculation indicates that the likelihood of stated over random paternity is $2 \times 10^{6}$ and $8 \times 10^{9}$ in the case of the son and daughter, respectively. Relative probability of the putative father being the true parent rather than an uncle of the two is respectively 17 and 339. We are satisfied, therefore, that autosomal recessive transmission occurred in the family we described.

The existence of several mendelian forms of hypophosphataemia provides strong evidence for the heterogeneity of renal phosphate transport systems. Our confirmation that autosomal recessive transmission truly occurred in the family we described strengthens the case that such heterogeneity exists.

\section{Reference}

${ }^{1}$ Stamp TCB, Baker LRI. Recessive hypophosphataemic rickets and possible aetiology of the vitamin D-resistant syndrome. Arch Dis Child 1976;51:360-5.

L R I BAKER

Department of Nephrology, St Bartholomew's Hospital, West Smithfield, London EC1A $7 B E$

T C B STAMP Royal National Orthopaedic Hospital, Stanmore, Middlesex 